\title{
ABUSO SEXUAL INFANTIL INTRAFAMILIAR: A AVALIAÇÃO PSICOLÓGICA COMO SUPORTE TÉCNICO JURÍDICO
}

ABUSO SEXUAL INFANTIL INTRAFAMILIAR: EVALUACIÓN PSICOLÓGICA COMO SOPORTE TÉCNICO JURÍDICO

INTRA-FAMILY CHILD SEXUAL ABUSE: PSYCHOLOGICAL ASSESSMENT AS LEGAL TECHNICAL SUPPORT

\section{Caroline Santos Cardoso}

Especialista em Psicologia Jurídica

Faculdade Pitágoras - Campus Eunápolis/BA

cardoso.carol@hotmail.com

ORCID - https://orcid.org/0000-0002-4049-5250

\section{RESUMO}

0 presente artigo traz à luz a violência intrafamiliar, sem a intenção de hierarquizar os tipos de violência, o enfoque do mesmo se dará sobre o abuso sexual em criança/adolescente, principalmente no que tange as questões jurídicas, fazendo um entrecorte entre as áreas da psicologia, do judiciário e das demais instâncias envolvidas, apresenta dessa forma, a necessidade de um trabalho interdisciplinar no combate as violações. A partir disso, discutir sobre atuação do psicólogo e sua metodologia, explanando sobre a importância da Avaliação Psicológica que pode auxiliar na erradicação da violência. 0 método utilizado foi o levantamento e revisão bibliográfica para o embasamento do estudo em questão, por meio de livros, artigos e revistas.

Palavras-chave: Avaliação psicológica; Abuso sexual; Intrafamiliar.

\section{RESUMEN}

Este artículo saca a la luz la violencia intrafamiliar, sin la intención de jerarquizar los tipos de violencia, cuyo foco estará en el abuso sexual en la niñez / adolescencia, especialmente en lo jurídico, haciendo un cruce entre las áreas de La psicología, el Poder Judicial y otras instancias involucradas, presenta así la necesidad de un trabajo interdisciplinario para combatir las violaciones. A partir de ahí, se comenta el desempeño y la metodología del psicólogo, explicando la importancia de la Evaluación Psicológica que puede ayudar en la erradicación de la violencia. El método utilizado fue la encuesta y revisión bibliográfica para sustentar el estudio en cuestión, a través de libros, artículos y revistas. 
Palabra clave: Evaluación psicológica; Abuso sexual; intrafamiliar.

\section{ABSTRACT}

The present article brings to light intrafamily violence, without the intention of hierarchizing the types of violence, the focus will be on sexual abuse in children /adolescents, especially in relation to legal issues, making an intersection between the areas of psychology, the judiciary and other involved bodies, thus presents the need for an interdisciplinary work in the fight against violations. From this to discuss about the performance of the psychologist and his methodology, explaining about the importance of Psychological Assessment that can help in the eradication of violence. The method used was the survey and bibliographic review for the basis of the study in question, through books, articles and journals.

Keywords: Psychological evaluation; Sexual abuse; Inside family.

\section{Introdução}

Não é novidade a ocorrência da violência no meio social e por vezes esta ocorre por parte daqueles que teriam o papel de cuidar e proteger. Desde os primórdios, os indivíduos cometem atos que vão de encontro e desestabilizam o "bem estar" da sociedade.

A violência submerge um excesso, uma brutalidade, um aprisionamento e a perda de autonomia com consequente perda da liberdade dos envolvidos. Agudelo (1990) apud Barbosa (2008, p.18) afirma sobre a violência, "ela representa um risco maior para a realização do processo vital humano: ameaça a vida, altera a saúde, produz enfermidade e provoca a morte como realidade ou como possibilidade próxima".

Sem a intenção de hierarquizar os tipos de violência, o presente artigo pretende debruçar-se sobre a violência de abuso sexual infantil intrafamiliar. 0 campo da violência doméstica é um "terreno movediço", como afirma Miranda (1998), em que se mesclam fantasia e realidade, cena que causa horror e curiosidade. Diante do número imenso de variáveis culturais e psíquicas, torna-se muito complexa a tarefa de bem lidar com este problema. 
O estudo da violência em suas causas, consequências, objetivos, justificativas, ganhou atualidade, parecendo depender desta compreensão a possibilidade de sobrevivência da humanidade e a construção de alternativas para um futuro melhor. Pode-se pensar que o abuso sexual intrafamiliar como toda ação ou omissão que prejudique o bem estar à integridade física, psicológica ou a liberdade e o direito ao pleno desenvolvimento de outro membro da família.

A violência sexual intrafamiliar, segundo Pires (2008), pode ser cometida dentro ou fora de casa por algum membro da família, incluindo pessoas que passam a assumir a função parental, ainda que sem laços de consanguinidade, e em relação de poder à outra. Portanto, quando se fala de violência intrafamiliar deve-se considerar qualquer tipo de relação de abuso/violência praticado no contexto privado da família contra qualquer um de seus membros. 0 autor ressalta que o conceito de violência intrafamiliar não se refere apenas ao espaço físico onde a violência ocorre, mas também às relações em que se constrói e efetua.

A violência intrafamiliar praticada contra crianças e adolescentes é uma prática histórica na sociedade brasileira, presente em todos os segmentos sociais. Venturin, Bazon e Biasoli-Alves (2004), ao examinarem a literatura sobre a violência intrafamiliar, mostram que os pesquisadores têm enfatizado que ela é a expressão do abuso de poder dos pais ou responsáveis, que coisificam as crianças e os adolescentes, fazendo deles objetos e desrespeitando os seus direitos fundamentais.

A psicologia pode ter seu papel em todas essas ações, seja nas práticas de pesquisa, na avaliação ou na intervenção propriamente dita. Especificamente no contexto jurídico, uma das atuações possíveis dos psicólogos é no sentido de assessorar os magistrados ao fornecerem informações que subsidiam suas decisões (Costa Penso, Legnani \& Sudbrack, 2009).

Nesse sentido, pretende-se na análise desse estudo mostrar as perspectivas e importância do profissional de psicologia, na avaliação psicológica, auxiliando de forma precisa o judiciário, na resolução e enfrentamento dos casos de violência sexual intrafamiliar. 


\section{Metodologia}

Com o acúmulo do conhecimento científico, surge a necessidade da Metodologia como um meio de organizar o saber acumulado pela humanidade. Ela oferece procedimentos e caminhos para se atingir a realidade teórica e prática de um determinado campo de estudo. Assim, novos conhecimentos surgem a partir de pesquisas realizadas com metodologia adequada a diferentes tipos de problemas, sejam eles da área acadêmica ou profissional.

No que diz respeito à metodologia utilizada neste artigo. 0 modelo é de cunho qualitativo que de acordo com Neves (1996, p.01), "não busca enumerar ou medir eventos. Ela serve para obter dados descritivos que expressam os sentidos dos fenômenos." Logo este método centra a atenção à revisão e pesquisa bibliográfica, que é a atividade de localização e consulta de fontes de diversas informações para a coleta de dados a respeito de determinado tema, através de livros, artigos, sites e revistas.

\section{Breve histórico}

A história social da infância no Brasil revela que, desde o tempo do Brasil colonial, tanto as crianças como os adolescentes têm vivido situações de violência dentro da família. Essa situação vem se reproduzindo por séculos e tem influenciado o pátrio poder, cujas concepções socializadoras e educativas estão baseadas em castigos físicos com o uso excessivo da autoridade familiar. (GONÇALVES, 2003).

A violência doméstica ou intrafamiliar tem sido um problema que atinge todas as classes sociais sem nenhuma distinção. Hoje está tão recorrente a mídia devido ao sofrimento indescritível que imputa as suas vítimas e que na maioria das vezes permanecem em silêncio e, também, que o abuso sexual pode impedir um bom desenvolvimento psicoafetivo da vítima. Nesse sentido Saffioti (1997) afirma que "a violência apresenta uma acentuada tendência à cronificação, mormente quando se trata de intrafamiliar" (p.155) 
De acordo com Marques (2017), o conceito de violência intrafamiliar define que a mesma consiste numa relação de abuso que se desenvolve entre indivíduos que possuem ligação familiar civil (cônjuges, padrasto e enteados, sogros, etc.) e ligação familiar de parentesco natural (pais e filhos, irmãos, etc.). Em geral, essa violência acontece tendo por base a diferença de poder que existe entre esses parentes.

Habigzang e Caminha (2004) apud Amazarray e koller (1998) falam de uma pesquisa sobre incesto, em São Paulo, conduzida por Cohen (1993). Revelam que, em uma amostra de 238 casos, $41,6 \%$ o pai era um agressor, seguidos pelo padrasto em $20,6 \%$, pelo tio em 13,8\%, pelo primo em 10,9\% e pelo irmão em 3,7\%. Enfatizaram que o incesto também pode ocorrer entre mãe-filho(a), em menos frequência e muitas vezes envolvendo quadros de psicose.

Refletindo sobre a família, com base nas prerrogativas da Convenção sobre os direitos da criança, que os autores trazem, é possível visualizar que nem todas as famílias defendem e promovem o sentimento de auto confiança da criança. Seria nesse ponto que a família deveria ser a representante de uma pedra basilar de qualquer estrutura psíquica, funcionando como grupo favorável ao crescimento e o bem estar dos seus componentes.

Os direitos da infância e da adolescência passam a ser garantidos, no Brasil, a partir de 1980, pela Constituição Federal de 1988, no art. 227; e, desde 1990, pelo Estatuto da Criança e do Adolescente, que os reconhece em sua cidadania como sujeitos de direitos, e em sua singularidade de pessoas em desenvolvimento. Meninos e meninas deixam de ser propriedade dos pais, como na legislação anterior (ECA, 1990).

A garantia integral a seus direitos passa a ser dever da família, da sociedade e do Estado. Assim, toda a sociedade é responsabilizada, e a ação ou a omissão que venha ferir os direitos de crianças e adolescentes é passível de rejeição social e punição legal (BRASIL, 2001).

No Brasil, houve avanços no enfrentamento da violência em geral, quando em 1998 o Ministério da Saúde reuniu diversos setores da sociedade para o debate acerca 
do tema. 0 fruto dessas discussões foi o lançamento, em 2001, da Política Nacional de Redução da Morbimortalidade por Violência e Acidentes. (BRASIL, 2001).

A política nacional estabelece ações de prevenção, além de atendimento especializado a grupos mais vulneráveis à violência, como a população infantil. Os acidentes infantis são eventos que podem gerar morte ou sequelas na criança, demandando assim atendimento nos serviços de saúde. (BRASIL, 2012).

Também prevê a tipificação e o diagnóstico da agressão, com a notificação dos maus-tratos a órgãos de defesa dos direitos infanto-juvenis, como por exemplo conselhos tutelares e Vara da Infância e da Família. Com base nesta política, foram criados os Núcleos de Prevenção da Violência e Promoção da Saúde, em 2004 (BRASIL, $2001 ; 2004)$.

É necessário, porém, que todos os profissionais que atuem na área da infância e da adolescência tenham conhecimento dos direitos estabelecidos pelo ECA (1990), bem como os fatores de risco envolvidos e que comprometem ao desenvolvimento infantil, para que possam intervir de forma precisa na prevenção e/ou interrupção do risco.

\section{Fatores de risco e proteção ao desenvolvimento infantil frente ao abuso sexual}

As crianças tornam-se mais vulneráveis frente a situações de risco, tais como abuso sexual, demonstra suscetibilidade individual, quando não contam com uma rede de apoio social e afetivo que seja eficaz e efetiva na prevenção de doenças e de características desadaptativas (KROM, 2000).

Essa vulnerabilidade pode potencializar os efeitos negativos de situações estressantes, mas por outro lado, a criança/adolescente que conseguir superar as adversidades é definida como resiliente, ou seja, capaz de buscar alternativas eficazes que a auxiliarão a enfrentar de forma satisfatória os eventos negativos da vida. "Ressalta que a resiliência possui bases tanto constitucionais quanto ambientais, sendo 
o resultado da interação das características individuais com a complexidade do contexto social". (HABIGZANG et al, 2006, p.380).

As condições ou variáveis relacionadas aos fatores de risco frente ao abuso sexual estão diretamente relacionadas com um comprometimento na desordem emocional e comportamental. Os autores Pesce, et al (2004) definem fatores de risco relacionados a infância como obstáculos individuais ou ambientais que aumentam a vulnerabilidade da criança e, dessa forma, a susceptibilidade para um resultado negativo no seu desenvolvimento.

Já para Garmezy (1985) apud Maia \& Williams (2005), os fatores de risco podem ser definidos por aqueles fatores que, quando presentes aumentam a probabilidade de a criança desenvolver problemas de ordem emocional e/ ou comportamental.

Esses fatores podem incluir atributos biológicos e genéticos da criança e/ou da família, bem como fatores da comunidade que influenciam, tanto o ambiente da criança quanto da sua respectiva família.

"afirma que nenhum outro fator de risco tem uma associação mais forte com a psicopatologia do desenvolvimento do que uma criança maltratada, ou seja, o abuso e a negligência causam efeitos profundamente negativos no curso de vida da criança." (BARNETT, 1997 APUD MAIA E WILLIAMS, 2005, P.92)

Para os autores, as sequelas do abuso e da negligência abrangem grande variedade de domínios do desenvolvimento, incluindo as áreas da cognição, linguagem, desempenho acadêmico e desenvolvimento socioemocional.

As crianças maltratadas, geralmente, apresentam déficit em suas habilidades de regular afeto e no comportamento geral. Os possíveis efeitos do abuso sexual, a curto prazo, podem aparecer problemas tais como: comportamento sexualizado, ansiedade, depressão, queixas somáticas, agressão, comportamentos regressivos (enurese, encoprese, birras, choros), comportamentos autolesivos, problemas escolares, entre outros.

Em longo prazo há risco de: depressão, ansiedade, prostituição, problemas com relacionamento sexual, promiscuidade, abuso de substâncias, ideação suicida, entre 
outros. A criança sente um mal estar profundo ao ser manipulada, desencadeando algo que ela não pode nomear e também não tem condições físicas nem psíquicas para compreender. (DIAMENT, A. e CYPEL, S., 1996).

Para os autores, os fatores que influenciam o prognóstico dos casos de abuso sexual infantil, pode-se destacar, a proximidade do agressor em relação à vítima, o número de agressores, a intensidade da violência empregada, a topografia do ato sexual em si, a duração do abuso, a frequência e o apoio dado à vítima pelo membro não agressor.

Os autores como Pesce et al, (2004); Maia \& Williams (2005); Sapienza \& Pedromônico (2005) afirmam que:

"os fatores de proteção ao desenvolvimento infantil, também nomeados de mediadores, são definidos como aqueles que podem promover uma alteração na resposta do indivíduo aos fatores de risco, favorecendo uma melhor adaptação da criança ao ambiente. Dentre suas diversas funções sinalizam-se como principais, a capacidade de estabelecer e manter a autoestima e auto eficácia individual, criação de recursos para enfrentar situações estressoras e redução do impacto dos riscos e seus efeitos".

Assim como os fatores de risco, Krom (2000) afirma que os de proteção também estão diretamente associados a fatores individuais, familiares (dos genitores) e sociais. Quanto aos atributos disposicionais da criança, acredita-se que características temperamentais, o grau de desenvolvimento da autoestima, orientação social positiva, capacidade de autocontrole, a inteligência acima da média e autonomia são sinalizadores de atributos protetivos aos desenvolvimentos.

Para Faleiros (2000), Uma família bem estruturada aponta características de estabilidade, respeito, autoconfiança, ausência de negligência e/ou abuso, suporte afetivo, apoio, bons relacionamentos no âmbito grupal e escolar, favorecimento do sentimento de pertença, pois a família funciona como apoio seguro da criança, assim possibilitando uma qualidade de vida e que possam diminuir as consequências negativas no desenvolvimento da criança. Logo tanto os fatores de risco e os de proteção interferem diretamente de maneira negativa ou positiva no desenvolvimento infantil e na qualidade de vida desta criança. 
De acordo com os autores compreende-se que os indivíduos que conseguem lidar de forma adequada com a adversidade possuem senso de eficácia e auto competência, são socialmente mais perceptivos do que seus pares que não conseguem lidar com as adversidades, são capazes de despertar atenção positiva das outras pessoas, possuem habilidades de resolução de problemas, possuem a habilidade de solicitar ajuda de outras pessoas quando necessário e possuem a crença de que podem influenciar positivamente o seu ambiente.

\section{A importância da avaliação psicológica}

De acordo com Silva (2003), a avaliação Psicológica é processo de coleta e análise de informações resultantes da aplicação de técnicas psicológicas, que podem incluir testes, entrevistas, questionários, observações, dentre outras. Por meio do processo pode-se analisar diferentes áreas que compõem a subjetividade do indivíduo, tais como: cognição, emoção e comportamento.

Já para Custódio, 2007 a avaliação psicológica é um processo que analisa a pessoa considerando seu meio social e cultural enfocando nas condições psicológicas do sujeito. Portanto, a escolha das técnicas a serem utilizadas deve ser feita de acordo com as especificidades de cada caso, bem como com o objetivo e a demanda que a avaliação visa atender.

Segundo Guedes (2012), nos casos de abuso sexual intrafamiliar, muitas vezes a criança ainda não tem a noção do que lhe ocorreu ou está acuada, com receio, culpa, medo e sofrendo ameaças. Logo se faz necessário na avaliação, entrevistar a criança/adolescente na busca de coletar informações, respeitando questões como idade, desenvolvimento cognitivo, linguagem, memória e sofrimento psíquico associado ao evento.

Nos casos que envolvem crianças introvertidas ou ainda sem linguagem oral, o brinquedo funciona como um facilitador para que elas expressem seus sentimentos 
relacionados à família e seu cotidiano. Organizar um ambiente físico adequado e acolhedor para a criança, demonstrar empatia e preocupação com o bem-estar dela, assim estabelece um vínculo de confiança para que a criança se sinta à vontade para falar. (AZEVEDO; GUERRA, 2005).

Explicar as razões da entrevista e como ela será feita, facilita a cooperação entre entrevistador e entrevistado. 0 profissional em hipótese alguma pode inserir seu próprio discurso no discurso da criança, respeitando seu tempo para o relato livre sobre a situação, sem interrompê-la. Esclarecer as lacunas do relato por meio de perguntas abertas, passando a perguntas fechadas apenas quando estritamente necessário.

No tocante aos testes, segundo Hongan (2006), os mais adequados são os projetivos que se trata de testes livres em que a criança terá um estímulo, seja uma imagem, seja uma frase, algo que faça com que ela crie uma resposta consciente ou inconsciente para o estímulo dado. Essa resposta será interpretada pelo psicólogo, mas este terá que seguir regras estabelecidas em manuais para a correção dos testes projetivos.

Entre as técnicas projetivas mais utilizadas estão: o teste de mancha de tinta de Rorschach, o teste de Apercepção Temática (TAT) teste de Apercepção infantil (CAT), teste Gestáltico Visuomotor de Bender, teste de Completar Frases, teste de Desenho de Figura humana, teste Casa-Árvore-Pessoa (HTP) e teste de Desenho da família em movimento (Hongan, 2006). Lembra-se que devem ser utilizados como base para uma avaliação junto com outras técnicas e a observação, pois o indivíduo não deve ser resumido a um resultado de teste.

\section{Resultados e discussão}

Este trabalho abordou potencialidades, dificuldades e necessidades da psicologia na avaliação de casos de abuso sexual contra crianças e adolescentes no 
contexto judiciário, bem como, os elementos que influenciam a tomada de decisões por psicólogos nestes casos.

Dessa forma, no contexto jurídico, caracteristicamente racional e objetivo, a psicologia pode fazer a diferença intermediando as necessidades do poder judiciário e as necessidades de seus usuários, humanizando o sistema de Justiça. (Guedes, 2012)

Os operadores da lei buscam a verdade real/material/histórica dos fatos e, por tal motivo, há, no Poder Judiciário, a necessidade de esclarecimento dos fatos alegados nos processos e o consequente direcionamento do sistema de Justiça para a punição, mais do que para a qualidade de vida dos sujeitos envolvidos (CESCA, 2004).

Segundo Brigham (1999), os juízes não valorizam as respostas que não sejam conclusivas ou que sejam vagas e evasivas. Entretanto, a perspectiva da proteção, que está evidente na busca contínua do auxílio de psicólogos, está ocupando um espaço cada vez maior na preocupação de operadores do direito.

\section{Conclusão}

O abuso sexual é um tema que tem sido amplamente tratado pela literatura científica, com grande atenção da psicologia para esse campo, tendo em vista o envolvimento dos psicólogos no acolhimento a esta população, aspecto que demanda um olhar atento por parte do Conselho Federal de Psicologia.

A avaliação, utiliza instrumentos, técnicas e uma escuta qualificada que o psicólogo faz junto a esta população no âmbito jurídico é um processo delicado e complexo, pois pode retomar a dor e o sofrimento do trauma vivenciado pela criança (revitimizando-a) (SILVA, 2003).

Em decorrência disso, observa-se tamanha discussão para realizar a melhor forma de acolhimento com crianças e adolescentes envolvidos em situação de violência e qual o papel do psicólogo nesse contexto. 
A perícia psicológica, considerada como um meio de prova, é uma modalidade de avaliação técnica e especializada comumente empregada na investigação de situações abusivas contra crianças e adolescentes, tendo em vista que, em muitos casos, não há materialidade suficiente que possa ser constatada por meio de um exame médico-legal (ROVINSKI; 2003, 2004).

Segundo Rovinski (2004) a perícia psicológica é uma das maneiras de acessar o histórico do examinando e sua sintomatologia, descartando outras ocorrências que possam ter desencadeado o quadro sintomático avaliado. Uma avaliação abrangente e compreensiva demonstra-se, portanto, imprescindível, devendo basear-se na integração de diferentes fontes de informação e de muitos indicadores.

De acordo com o que o autor traz, percebe-se que a avaliação psicológica somada aos aportes técnicos e teóricos da psicologia tem uma contribuição importante e positiva, tanto para o profissional de psicologia que aplica, bem como, no auxílio das vítimas na superação da violência e para o jurídico que amplia a visão acerca do funcionamento mental e das questões emocionais implicadas em uma vivência de abuso sexual.

Ressaltando que os autores da área, defendem a importância do respeito ao silêncio enquanto um limite diante do que foi vivido, além da necessidade de muitos em esquecer-se do abuso como estratégia defensiva para lidar com aquilo que se mostra intolerável e exagerado advindo do trauma.

Acredita-se que tal conhecimento pode colaborar para o desenvolvimento de estratégias mais sensíveis e menos invasivas para esta avaliação, que visem o acolhimento, a empatia e respeito ao ritmo e ao processo evolutivo da criança. Assim, é possível minimizar os possíveis danos secundários que elas poderiam vir a sofrer.

\section{Referências}

AGUDELO, S. F. 'La violência: un problema de salud pública que se agrava en la region'.1990 Boletin Epidemiologico de la OPS. 
AZEVEDO, Maria Amélia; GUERRA, Viviane Nogueira de Azevedo. Infância e violência doméstica: fronteiras do conhecimento. São Paulo: Cortez, 2005.

BRASIL. Estatuto da Criança e do Adolescente: Lei 8.069/90, de 13 de julho de 1990. Brasília: Senado Federal, 1990.

BRASIL. Constituição Federal. Constituição da República Federativa do Brasil. Brasília, DF: Senado, 1988.

BRASIL. Políticas Nacional da Redução da Morbimortalidade por acidentes e Violências. Diário Oficial da União n. 96.18 maio, seção 1e. Brasília, DF: Ministério da Saúde, 2002.

BRASIL. Ministério da Saúde. Secretaria de Política de Saúde. Promoção da Saúde. Brasília.2012. Texto mimeo.

BRIGHAM, J.C. (1999). What is forensic Psychology, anyway? Law and Human Behavior, 23 (3), 273-298.

CESCA, T.B. (2004). 0 papel do psicólogo jurídico na violência intrafamiliar: Possíveis articulações. Psicologia \& Sociedade, 16 (3), 41-46.

CONSELHO FEDERAL DE PSICOLOGIA CFP. Código de Ética Profissional do Psicólogo. Agosto 2005. Disponível em: http://site.cfp.org.br/wpcontent/uploads/2012/07/codigo_etica.pdf. Acesso em 22 de março de 2018.

CONSELHO FEDERAL DE PSICOLOGIA CFP. Resolução no 010/2010 - Institui a regulamentação da Escuta Psicológica de Crianças e Adolescentes envolvidos em situação de violência, na Rede de Proteção. Disponível em: http://www.crpsp.org.br/portal/orientacao/resolucoes_cfp/fr_cfp_010-10.aspx. Acesso em 26 de março de 2018.

COSTA, Juliana Guimarães. Resenha do livro: Por trás da máscara familiar (1989). Disponível em: <http://icassia.sites.uol.com.br/resenhaportrasdamascara.html> Acesso em 23 de Março de 2018.

CUSTÓDIO, E. M. (2007). Avaliação Psicológica: ensino e pesquisa na década de 1960. Boletim da Academia Paulista de Psicologia, 2, 49-60.

DIAMENT, A. e Cypel, S. Neurologia Infantil. 3a edição. Livraria Atheneu, 1996.

FALEIROS, E. (Org.). 0 abuso sexual contra crianças e adolescentes: os (des)caminhos da denúncia. Secretaria Especial de Direitos Humanos, Subsecretaria de Promoção dos Direitos da Criança e do Adolescente. Brasília, 2000.

GONÇALVES, Hebe Signorin. Infância e violência no Brasil. Rio de Janeiro: Nau/ FAPERJ, 2003. 
GUEDES, L.T. (2012). A busca da verdade real e o direito de não produzir prova contra si mesmo. Revista Jus Navigandi, 17 (3282), 1-4.

HABIGZANG, Luísa Fernanda \& CAMINHA, Renato Maiato. Abuso sexual contra crianças e adolescentes: conceituação e intervenção clínica. São Paulo: Casa do Psicólogo, 2004.

HABIGZANG, L. F. et al. Abuso Sexual Infantil e Dinâmica Familiar: Aspectos Observados em Processos Jurídicos. Psicologia: Teoria e Pesquisa, v.21, n.3, p.341$348,2005$.

HOGAN, T. Introdução à prática de testes psicológicos. LTC. Rio de Janeiro, 2006.

KROM, Marilene. Família e mitos - prevenção e terapia: resgatando histórias. São Paulo: Summus, 2000.

MARQUES, J.R. Conheça o conceito de violência intrafamiliar e suas consequências. Disponível em: < https://blog.mettzer.com/referencia-de-sites-eartigos-online/> Acesso em: 15 de abril de 2018.

NEVES, J. L. Pesquisa qualitativa - características, uso e possibilidades. Cadernos de pesquisa em administração, São Paulo. V. 1, no 3, 2º́sem. 1996

PESCE, R.P.; ASSIS, S.G.; SANTOS, N.; OLIVEIRA, R.V.C. Risco e Proteção. Em busca de um equilíbrio promotor de resiliência. Psicologia: teoria e Pesquisa. Vol.2, maio/ago.2004.

PIRES, JMA. Violência na infância - aspectos clínicos. In: Violência Doméstica, Violência contra Crianças e Adolescentes na Grande Porto Alegre. Amencar, São Leopoldo, 2008.

ROVINSKI, S. L. R. Perícia psicológica na área forense. In: CUNHA, J. A. (Org.). Psicodiagnóstico-V. Porto Alegre: Artmed, 2003. p. 183-195.

ROVINSKI, S. L. R. Fundamentos da perícia psicológica forense. São Paulo: Vetor, 2004.

SAFFIOTI, Heleieth I. B. No fio da navalha: violência contra crianças e adolescentes no Brasil atual. In: MADEIRA, Felícia Reicher. Quem mandou nascer mulher? Estudos sobre crianças e adolescentes pobres no Brasil. Rio de Janeiro: Record/Rosa dos Tempos, 1997.

SILVA, D. M. P. (2003). Psicologia jurídica no processo civil brasileiro: a interface da Psicologia com Direito nas questões de família e infância. São Paulo: Casa do Psicólogo, 2003

VENTURINI, Fabiola Perri; BAZON, Marina Rezende; BIASOLI-ALVES, Zélia Maria Mendes. Família e violência na ótica de crianças e adolescentes. Estud. pesqui. psicol., Rio de Janeiro, v. 4, n. 1, jun. 2004, p.20-33. 